\title{
In situ equilibrium pore-water pressures derived from partial piezoprobe dissipation tests in marine sediments
}

\author{
Nabil Sultan ${ }^{a, b, ~}{ }^{*}$ Sara Lafuerza ${ }^{a, 1}$ \\ ${ }^{a}$ Ifremer, REM/GM/LES, France. \\ ${ }^{\mathrm{b}}$ Faculty of Engineering, Beirut Arab University, Tripoli Branch, Lebanon. \\ ${ }^{1}$ Present address : Fugro GéoConsulting S.A., Nanterre, France. \\ *: Corresponding author : Nabil Sultan, email addresses : nabil.sultan@ifremer.fr ; n.sultan@bau.edu.lb
}

\begin{abstract}
:
Excess pore water pressure has a significant effect on submarine slope stability and sediment deformation, and therefore, its in situ equilibrium measurement is crucial to carry out accurate slope stability assessments and to derive accurately design geotechnical parameters. In situ equilibrium pore water pressure is usually obtained from pore pressure decay during piezocone tests. However, submarine shelves and slopes are often characterized by the existence of low-permeability (finegrained) sediments involving long dissipation tests which are an important issue for offshore operational costs. Consequently, short-term/partial dissipation tests are usually performed and in situ equilibrium pore water pressures are predicted from partial measurements.
\end{abstract}

Using a modified cavity expansion approach, this paper aimed to predict for 4 different sites the in situ equilibrium pore water pressures. Comparison between predicted and observed in situ equilibrium pore water pressures allowed to define a guide to evaluate the minimum time required to perform short-term dissipation tests for a given marine sediment. The main finding of this note is that the second derivative of pore pressure, $\mathrm{u}$, versus the logarithmic of time, $\mathrm{t}, \frac{\partial^{2} u}{\partial \ln (t)^{2}}$ must be positive in order to calculate accurately from partial measurements the in situ equilibrium pore water pressures.

Key words: cavity expansion ; dissipation tests ; marine sediment ; piezoprobe ; pore water pressure 


\section{Résumé:}

L'excès de pression interstitielle a un effet significatif sur la stabilité des pentes sous-marines et sur la déformation des sédiments, alors sa mesure in-situ à l'équilibre est cruciale pour réaliser des évaluations exactes de la stabilité des pentes et pour dériver adéquatement les paramètres géotechniques de conception. La pression interstitielle in-situ à l'équilibre est généralement obtenue à partir de la diminution de la pression interstitielle lors d'essais en piézocône. Cependant, les plateaux et pentes sous-marins sont souvent caractérisés par l'existence de sédiments à faible perméabilité (à granulométrie fine) qui engendrent des tests de dissipation de longue durée, ce qui représente une problématique pour les coûts d'opération en mer. Ainsi, des essais de dissipation partiels ou de courte durée sont généralement réalisés et les pressions interstitielles in-situ à l'équilibre sont prédites à partir de mesures partielles. Grâce à une approche modifiée de l'expansion d'une cavité, cet article tente de prédire les pressions interstitielles in-situ à l'équilibre pour quatre sites différents. Des comparaisons entre les pressions interstitielles à l'équilibre prédites et celles mesurées in-situ ont permis de définir un guide servant à évaluer le temps minimal requis pour réaliser des essais de dissipation de courte durée pour un sédiment marin donné. Le résultat principal de cette note est que la dérivée double de la pression interstitielle, $u$, versus le logarithme du temps, $t, \partial^{2} u / \partial \ln (t)^{2}$ doit être positive afin de calculer exactement la pression interstitielle in-situ à l'équilibre à partir de mesures partielles.

Mots-clés : expansion d'une cavité ; essais de dissipation ; sédiment marin ; piézosonde ; pression interstitielle 


\section{List of symbols}

$\beta$ : describes the change of the coefficient of consolidation with the consolidation level

$\mathrm{C}_{\mathrm{h}}$ : consolidation coefficient of plasticised zone

$\mathrm{C}_{\mathrm{hs}}$ : consolidation coefficient of zone affected by shear

$\mathrm{C}_{\mathrm{i}}$ : the coefficient of consolidation for isotropic drainage

$\Delta \mathrm{u}$ : excess pore pressure

$\Delta u_{n}:$ pore pressure component due to the normal octahedral stress

$\Delta \mathrm{u}_{\text {shear }}$ pore pressure component due to the shear stress

E: Young modulus

G: shear modulus

$\mathrm{I}_{\mathrm{r}}$ : soil rigidity index

$v$ : Poisson's ratio

$r_{0}$ : radius of the piezoprobe

$r_{p}$ : radius of plasticized zone.

$r_{s}$ : radial thickness of the zone affected by shear

$\mathrm{S}_{\mathrm{u}}:$ undrained shear strength

t: time

$\mathrm{U}$ : degree of pore water dissipation

u: penetration-induced pore pressure

$\mathrm{u}_{\mathrm{eq}}$ : in situ equilibrium pore water pressure

$\mathrm{u}_{\mathrm{i}}$ : pore-water pressure measured by pore pressure sensor at time $0^{+}$

$\mathrm{u}_{\mathrm{in}}$ : pore-water pressure generated at the interface between zone affected by shear and plasticized at time $0^{+}$ 


\section{Introduction}

Excess pore water pressure is considered as one of the most important external factor controlling occurrences of submarine slope instabilities (Masson et al. 2010). Indeed, sediments shear strength depends on the vertical effective stress, and therefore, can be drastically reduced if pore water pressures in excess of hydrostatic occur, according to the effective stress principle.

Several sources can be at the origin of these excess pore pressures: prevention of fluid drainage during rapid sedimentation periods (Dugan and Flemings 2000; Long et al. 2007; Leynaud et al. 2007; Flemings et al. 2008; Schneider et al. 2009), fluid seepage (Dugan and Germaine 2008; Stegmann et al. 2011; Sultan et al. 2011), gas hydrate dissociation/dissolution (Nixon and Grozic 2007; Sultan et al. 2010), earthquake shaking (Biscontin and Pestana 2006; Lee et al. 2007; Haeussler et al. 2008; Sultan et al. 2008) and gas exsolution during low sea-level stands (Lafuerza et al. 2009; Riboulot et al. in press). Several examples of submarine slope instabilities associated to excess pore water pressures have been reported in literature: for instance the slope failures in the Norwegian continental slope (Kvalstad et al. 2005), the New Jersey continental slope (Dugan and Flemings 2002), the Mississippi Canyon (northern Gulf of Mexico, Dugan and Germaine 2008), or the large slope failures related to volcanic islands (Urgeles et al. 1999).

Measurements of in situ equilibrium pore water pressures $\left(u_{e q}\right)$ are usually obtained from pore pressure decay during piezoprobe measurements. In this paper, the generic term piezoprobe is used to include free-fall piezometers (Urgeles et al. 2000; Stegmann et al. 2007; Sultan et al. 2010; Stegmann et al. 2011), piezocones (Burns and Mayne 1998; Arulrajah et al. 2005), or other devices operated in boreholes. On the other hand, laboratory measurements of the preconsolidation pressures can provide approximate estimations of $u_{\text {eq }}$ (Schneider et al. 2009) when sediment samples are not affected by disturbance (Lunne et al. 2006; Lafuerza et al. 2009). Geophysical methods may be also used for pore water pressure estimation, but correlations can be limited since their accuracy can be insufficient for geotechnical purposes (Strout and Tjelta 2005).

In low-permeability normally consolidated clayey-sediments, piezoprobe penetration compresses and shears the surrounding sediments under undrained conditions thus generating excess pore water pressures. Once piezoprobe insertion stops, penetrationinduced pressures $(u)$ dissipate monotonically with time, (similar to the curve observed during one-dimensional consolidation tests) and eventually $u_{\text {eq }}$ is reached (Figure 1). In contrast, dissipation tests performed in overconsolidated sediments usually show dilatory behaviour, with $u$ increasing from the initial measured value to a maximum and then decreasing to $u_{\text {eq }}$ (Figure 1 ). The decay of $u$, which can be very slow in low-permeability marine clays (e.g. $5.3-15.2 \times 10^{-7} \mathrm{~m}^{2} / \mathrm{s}$ in Norwegian clays, Lacasse and Lunne 1982), is generally used to infer $u_{\text {eq }}$ and the coefficient of consolidation. Piezoprobe radius $\left(r_{0}\right)$ also affects dissipation times, since the deformed/compressed region around the piezoprobe increases with the radius, generating higher $u$ and longer dissipation paths, and therefore, longer dissipation times. Offshore dissipation tests usually involve short term measurements since the needed time to reach in situ equilibrium pore water pressure values can be a significant issue for offshore operational costs. Resulting partial dissipation data require extrapolation to obtain $u_{\text {eq }}$, which can be addressed by means of empirical and/or theoretical models.

The empirical extrapolation frequently used to interpret partial dissipation data is the one based on the inverse dissipation time $\frac{1}{t}$ (Davis et al. 1991). Flemings et al. (2008) show that 
the inverse of square root of time $\frac{1}{\sqrt{t}}$ requires much less time to achieve accurate extrapolated values compared to the inverse time method proposed by Davis et al. (1991), which tends to overestimate $u_{\text {eq }}$ for low-permeability sediments (Long et al. 2007). However, there are no theoretical foundations to these empirical approaches and theoretical methods are considered more appropriate to determine $u_{\text {eq }}$. The most common theoretical approaches are: (i) the cavity expansion theory and (ii) the Strain Path Method (SPM, Baligh, 1986). As discussed in Burns and Mayne (2002), simplified theoretical approaches using cavity expansion and critical-state soil mechanics (Burns and Mayne, 1998) provide less complex solutions to interpret dissipation data than other methods based on the SPM (Sully et al. 1999).

During the last decade the Institut Français de Recherche pour l'Exploitation de la Mer (Ifremer) performed an important number of short- and long-term dissipation tests on several continental margins. In order to better constrain predictions of $u_{\text {eq }}$ for available data sets and future acquisitions, this work aims to propose a guide to determine the minimum needed time for offshore pore water decay tests to ensure accurate predictions of $u_{\mathrm{eq}}$. The proposed analyses are based on complete pore water pressure dissipation data gathered with the Ifremer piezometer in fine-grained marine sediments from three distinct continental slopes. According to the current state of the art in dissipation pore water decay modelling, the model based on the cavity expansion approach of Burns and Mayne (1998) is used.

\section{Tools and Data set}

Pore water pressures dissipation data used in the present work were acquired using the Ifremer piezometer from four different sites (Table 1). The Ifremer piezometer is a free-fall piezoprobe ballasted with lead weights to penetrate a range of sediment types. Pore fluid pressures are measured relative to hydrostatic pressure at maximum twelve pressure ports on a $0.06 \mathrm{~m}$ diameter lance (cone radius $r_{0}=0.03 \mathrm{~m}$ ) consisting on single rods of $0.75 \mathrm{~m}, 1.5$ $\mathrm{m}$ and $3 \mathrm{~m}$ in length. The deepest pore water sensor is at $0.5 \mathrm{~m}$ from the piezometer tip. The pressure ports are connected to the open seawater with differential pore pressure transducers that provide measurements with a resolution of $\pm 0.2 \mathrm{kPa}$.

The 4 set of data, used in the present note, were acquired from: (i) Site A: the Nice slope (NW Mediterranean); (ii) Sites B and C: Niger delta and (iii) Site D: the Algerian margin (SW Mediterranean). Pore water pressure measurements from the Nice slope (site A) correspond to the piezometer site PZ2Y03-P7 deployed at $49 \mathrm{~m}$ of water depth with 7 pressure sensors (P1 to P7) at depths $0.8,2.35,3.9,5.45,7.0,8.55$ and $8.58 \mathrm{~m}$ below seafloor (mbsf), respectively. For this work, only pore water pressure data at sensor P7 are used. For the Niger delta sites (sites B and C), the piezometer tests correspond to sites ER-PZS12-P5 and GM-PZ05-P4 deployed respectively at $746 \mathrm{~m}$ and $1147 \mathrm{~m}$ water depth and equipped with pressure sensors $\mathrm{P} 1$ to $\mathrm{P} 5$ at depths $0.83,3.88,6.93,9.98$ and $11.48 \mathrm{mbsf}$ for B and with pressure sensors $\mathrm{P} 1$ to $\mathrm{P} 7$ at depths $0.83,3.88,6.93,8.48,10.03,10.83$ and 10.86 for $\mathrm{C}$. Pore water pressures dissipation data selected for this study correspond to data recorded at the sensor P5 for site B and P4 for site C. Finally, dissipation pore water data from the Algerian margin (Site D) comprise measurements at site PZ1-15-P3 deployed at $2280 \mathrm{~m}$ of water depth and equipped with pressure sensors P1 to P4. For this work, only pore water pressure data at sensor P3 (5.5 mbsf) are used. 


\section{Pore water pressure build-up and dissipation: theoretical analysis and modeling}

\subsection{Pore pressure build-up during piezoprobe penetration}

The pore fluid pressure $(u)$ recorded by a pressure sensor corresponds to an excess pore pressure $(\Delta \mathrm{u})$ generated by the piezoprobe insertion and $u_{\text {eq }}$ which is assumed to be constant during the dissipation process $\left(u=\Delta u+u_{e q}\right)$. The generated $\Delta \mathrm{u}$ is caused by: (i) a mean normal octahedral stress resulting from the displacement of the soil and fluid by the penetrating piezoprobe and (ii) a shear stress at the sediment-piezoprobe interface (Burns and Mayne, 1998). As a result, the measured pore pressure during dissipation tests is expressed as the sum of three components:

$$
u=\Delta u+u_{e q}=\Delta u_{n}+\Delta u_{\text {shear }}+u_{e q}
$$

where $\Delta \mathrm{u}_{\mathrm{n}}$ and $\Delta \mathrm{u}_{\text {shear }}$ are the pore pressure components due to the normal octahedral stress and the shear stress, respectively. Under the piezoprobe tip, the largest effect on the magnitude of $u$ is due to the $\Delta u_{n}$ component and the relative changes in $\Delta u_{\text {shear }}$ are small. In contrast, along the piezoprobe shaft, limited to a thin annulus next to the body of the piezoprobe, $\Delta \mathrm{u}_{\text {shear }}$ becomes a significant portion of the induced $u$ (Burns and Mayne, 1998).

\subsection{Cavity expansion and pore pressure decay}

In order to model pore water dissipation data, Burns and Mayne (1998) use the cavity expansion theory to represent the normal pore pressure component $\Delta u_{n}$ and the Modified Cam Clay theory to quantify the shear pore pressure component $\Delta \mathrm{u}_{\text {shear }}$. The cavity expansion theory considers that during piezoprobe insertion (under undrained conditions) a plasticized zone is generated at the piezoprobe tip due to a cavity expansion as function of the soil rigidity index $I_{r}$. The cavity can be cylindrical or spherical (see Figure 2). Accordingly, the radius of the plasticized zone $\left(r_{p}\right)$ is expressed as:

$$
\begin{aligned}
& r_{p_{s p h}}=r_{0} \cdot\left[I_{r}\right]^{\frac{1}{3}}=r_{0}\left[\frac{E}{2(1+v) S_{u}}\right]^{\frac{1}{3}}=r_{0}\left[\frac{G}{S_{u}}\right]^{\frac{1}{3}} \\
& r_{p_{c y l}}=r_{0} \cdot[I r]^{\frac{1}{2}}=r_{0}\left[\frac{E}{2(1+v) S_{u}}\right]^{\frac{1}{2}}=r_{0}\left[\frac{G}{S_{u}}\right]^{\frac{1}{2}}
\end{aligned}
$$

where ${ }_{\text {sph }}$ and ${ }_{\text {cyl }}$ denote the cavity type (spherical or cylindrical), $r_{0}$ is the radius of the piezoprobe, $E$ is the Young modulus, $v$ is the Poisson's ratio, $\mathrm{S}_{u}$ is the undrained shear strength and $G$ is the shear modulus.

Typical records of pore fluid pressure (u) dissipation show magnitudes of $u$ either monotonically decreasing with time from the initial reading or temporary increasing followed by a monotonically decreasing with time (Figure 1). The dissipation of $u$ can be modelled using the following consolidation equations for spherical (equation 4) and cylindrical (equation 5) cases (Burns and Mayne, 1998): 


$$
\frac{\partial u}{\partial t}=C_{i} \frac{2}{r} \frac{\partial u}{\partial r}+C_{i} \frac{\partial^{2} u}{\partial r^{2}}
$$

$$
\frac{\partial u}{\partial t}=\frac{C_{h}}{r} \frac{\partial u}{\partial r}+C_{h} \frac{\partial^{2} u}{\partial r^{2}}
$$

where $C_{i}$ is the coefficient of consolidation for isotropic drainage that acts in the spherical cavity and $r$ the radius of the sheared and plasticized zones (Figure 2). The coefficient of consolidation for isotropic drainage $C_{i}$ is equal to the horizontal coefficient of consolidation $C_{h}$ when considering the cylindrical cavity (equation 5). In the following only the cylindrical consolidation equation is considered since as it was mentioned previously the deepest sensor of the Ifremer piezometer is at $0.5 \mathrm{~m}$ from the piezometer tip which is more than 16 times the radius of the piezoprobe. However, a comparison between the cylindrical and spherical solutions will be presented in the discussion paragraph.

In the present work, two main changes were made to the Burns and Mayne (1998) theory by including two distinct zones characterized by two different consolidation coefficients: the zone affected by shear is characterized by a consolidation coefficient of $\mathrm{C}_{\mathrm{hs}}$ and a radial thickness $r_{s}$ (Figure 2) and the plasticized zone by a consolidation coefficient $C_{h}$. Also, the initial excess pore pressure generated by the probe penetration at the interface between the zone affected by shear and the plasticized zone (called $u_{i n}$ in Figure 2 ) is considered as an unknown of the problem. The second main change is that the coefficient of consolidation $\mathrm{C}_{\mathrm{h}}$ is considered to change linearly during the dissipation process (from $C_{h i}$ to $(1-\beta) \times C_{h i}$ ) and it may decrease with time according to the following equation (Abuel-Naga and Pender, 2012):

$$
C_{h}=C_{h i} \cdot[1-\beta \cdot U]=C_{h i} \cdot\left\lfloor 1-\beta \cdot \frac{u_{i}-u}{u_{i}-u_{e q}}\right\rfloor
$$

Where $u$ is pore water pressure, $U$ is the degree of pore water dissipation and $\beta$ corresponds to the Abuel-Naga and Pender (2012) $i_{c v}$ dimensionless parameter. $\beta\left(=i_{c v}\right)$ describes the change of the coefficient of consolidation with the consolidation stress increment.

\subsection{Numerical scheme and optimization method}

The aim of the present work is to predict accurately $u_{\text {eq }}$ based on partial dissipation tests. In order to fulfil this main goal, equations 5 and 6 were numerically solved by approximating all the derivatives by finite differences and by using an explicit numerical method. A numerical scheme similar to the one proposed by Kim and Lee (200) was implemented (Figure 3) and solved using the fortran programming language.

The calculation of the pore pressure evolution with time at a given sensor leads to consider numerically the change in pore pressure in space $r$ (with $r_{0} \leq r \leq r_{p}$ ) and time $t$ (with $t \geq 0$ ). In addition, solution to equations 5 and 6 requires specification of boundary conditions at $r=r_{0}$, $r=r s$ and $r=r_{p}$, and initial conditions at time $t=0$. The limit conditions are: impermeable wall at $r=r_{0}$, pore pressure equal $u_{\text {in }}$ at $r=r 0+r s$ and $t=0$ and $u=u_{\text {eq }}$ at $r=r_{p}$. At $t=0$, the pore pressure $\mathrm{u}_{\mathrm{i}}$ at $\mathrm{r}=\mathrm{r}_{0}$ is measured by the piezoprobe and considered as an input in the developed software. 
The geotechnical parameters required for the numerical calculation are: the coefficient of consolidations $\mathrm{C}_{\mathrm{h}}$ and $\mathrm{C}_{\mathrm{hs}}$, the $\beta$ dimensionless parameter and the rigidity index Ir which can be calculated from the undrained shear strength $S u$ and the shear modulus $G$.

From above, it is obvious that a partial dissipation curve can be used to determine the main unknown which is $u_{\text {eq. }}$. However, very often, pore pressure measurements are carried out in areas where the geotechnical properties of the sediment are not completely characterized and therefore the recorded partial dissipation curve must be used to determine 6 unknowns: $\mathrm{C}_{\mathrm{h}}, \mathrm{C}_{\mathrm{hs}}, \beta, \mathrm{Ir}, \mathrm{u}_{\mathrm{in}}$ and $\mathrm{u}_{\mathrm{eq}}$. In this work, the application of the Least Square Method in back analysis is used in order to derive the six unknowns.

An iterative procedure is necessary to determine the more appropriate values for the 6 unknowns by means of an optimization algorithm. This becomes a numerical problem of finding a set of variables that gives the minimum error between measured and predicted pore pressure at a given sensor.

The uniqueness of the solution and therefore the correctness of the prediction of the six unknowns depend on the time length of the dissipation test. The developed numerical scheme is used in order to define the minimum pore water pressure dissipation data needed for a given site to define the 6 unknowns with acceptable uncertainties.

\section{Calculations of in situ equilibrium pore water pressure}

For the four sites (A, B, C and D), different series of calculations with different time series between 1 and $36 \mathrm{~h}$ of pore water pressure decay are considered to calculate $u_{\text {eq. }}$. For each series, $4 \times 10^{7}$ back calculations were carried out in order to define, by the application of the Least Square Method, the different unknowns of the problem and mainly $u_{\text {eq. }}$. The ranges of used parameters are presented in Table 1.

\subsection{Site A - Nice slope}

Eleven series of calculations with 11 different time series of data were considered. Because of the monotonically decrease of pressure with time at site $A$, the thickness of the zone affected by shear is considered equal to 0 . The first three series of calculations, presented in Figure 4-a (1h, $2 \mathrm{~h}$ and $3 \mathrm{~h}$ of pore water pressure decay) show a clear discrepancy between the predicted and measured $u_{\text {eq }}$. In contrast, Figure 4-b shows that for longer times series ( $4 \mathrm{~h}, 6 \mathrm{~h}, 8 \mathrm{~h}$ and $10 \mathrm{~h}$ ), the predicted curves of $\mathrm{u}$ fit very well with the observed data.

In Figure 5-a are shown the measured pore pressure $u$, the first derivative $\frac{\partial u}{\partial \ln (t)}$ and second derivative $\frac{\partial^{2} u}{\partial \ln (t)^{2}}$ of $u$ versus the logarithmic of time. The $\frac{\partial^{2} u}{\partial \ln (t)^{2}}$ equal to 0 at $11919 \mathrm{~s}$ (Table 2) corresponds to an inflection in the curve $\mathrm{u}-\ln (\mathrm{t})$. This inflection point is the limit between the concave down and concave up sections of the $u-\ln (\mathrm{t})$ curve. Figure 5-b compares the measured $u_{\text {eq }}$ (dashed line) to predicted $u_{\text {eq }}$ for the eleven different series of calculations. For each series of calculations, the predicted $u_{\text {eq }}$ values where the error is less than 1.5 times the minimum error obtained using the $4 \times 10^{7}$ back calculations are plotted. It is clear that an important discrepancy exists in the $u_{\text {eq }}$ prediction for the first 3 series while a good repeatability in the $u_{\text {eq }}$ predictions can be observed for the last 8 series of calculations. 
The results of modelling calculations using the time series of data until $\frac{\partial^{2} u}{\partial \ln (t)^{2}}=0$ are presented in Table 3 and the $\left|u_{e q}-u_{\text {eq-cal }}\right|$ was found equal to $3.5 \mathrm{kPa}$. The extrapolated $u_{\text {eq-ext }}$ from the same time series of data using the Davis et al. (1991) method gave a greater error: $\left|u_{\text {eq }}-u_{\text {eq-ext }}\right|$ was found equal to $6.4 \mathrm{kPa}$. These results confirmed what was observed by Long et al. (2007) about the overestimation of $u_{\text {eq }}$ using the Davis et al. (1991) method.

\subsection{Site B - Niger delta}

For site B, 14 series of calculations with different time series of data were considered. The shape of the dissipation curve shows a temporary increase followed by a decrease of the pore water pressure (Figure 6), suggesting that the zone affected by shear is non-negligible. In Figure 6-a are plotted 6 different series $(2 \mathrm{~h}, 4 \mathrm{~h}, 6 \mathrm{~h}, 8 \mathrm{~h}, 12 \mathrm{~h}$ and $15 \mathrm{~h}$ of pore water pressure decay) illustrating an important discrepancy between the predicted and the observed $u_{\text {eq. }}$. On the other hand, a very good agreement is shown in Figure 6-b, where four different series of calculations using longer time series $(24 \mathrm{~h}, 28 \mathrm{~h}, 30 \mathrm{~h}$ and $36 \mathrm{~h}$ of pore water pressure decay) are compared to the measured pore water dissipation data.

Figure 7 illustrates, as observed for the site A, that an important discrepancy exists in the $u_{\text {eq }}$ prediction for the series of calculations series where the time series of data used correspond to $\frac{\partial^{2} u}{\partial \ln (t)^{2}}<0$. These divergences between predicted and observed $u_{\text {eq }}$ decrease significantly for $\frac{\partial^{2} u}{\partial \ln (t)^{2}}>0$. The results of modelling calculations using the time series of data until $\frac{\partial^{2} u}{\partial \ln (t)^{2}}=0$ and corresponding to $\mathrm{t}=46304 \mathrm{~s}$ (Table 2) are presented in Table 3 and the $\left|u_{\text {eq }}-u_{\text {eq-cal }}\right|$ was found equal to $1.9 \mathrm{kPa}$. The use of the Davis et al. (1991) extrapolation method based on the same time series gave $\left|u_{\text {eq }}-u_{\text {eq-ext }}\right|$ equal to $9 \mathrm{kPa}$.

\subsection{Site C - Niger delta}

Figure 8 and Figure 9 show the calculation results for site $C$. Because of the shape of the $u$ $\ln (\mathrm{t})$ curve, the thickness of the zone affected by shear is considered equal to 0 . As for the previous two sites, the important discrepancy between predicted and observed $u_{\text {eq }}$ decreases significantly when the time series of data used in the calculation exceeds the time at which $\frac{\partial^{2} u}{\partial \ln (t)^{2}}=0 \quad(\mathrm{t}=31350 \mathrm{~s}-$ Table 2$)$. The results of modelling calculations and extrapolation (Davis et al. 1991 method) using the time series of data until $\frac{\partial^{2} u}{\partial \ln (t)^{2}}=0$ are presented in Table 3. The $\left|u_{\text {eq }}-u_{\text {eq-cal }}\right|$ was found equal to $0.4 \mathrm{kPa}$ while the $\left|\mathrm{u}_{\text {eq }}-\mathrm{u}_{\text {eq-ext }}\right|$ was found equal to $2.7 \mathrm{kPa}$.

\subsection{Site D - Algerian margin}

Figure 10 and Figure 11 show the calculation results for the site $D$. The zone affected by shear is considered equal to zero due to the shape of the $u-\ln (t)$ curve. The important 
discrepancy between predicted and observed $u_{\text {eq }}$ decreases significantly when the time series of data used in the calculation exceeds the time at which $\frac{\partial^{2} u}{\partial \ln (t)^{2}}=0 \quad(\mathrm{t}=31377 \mathrm{~s}-$

Table 2). The results of modelling calculations and extrapolation (Davis et al. 1991 method) using the time series of data until $\frac{\partial^{2} u}{\partial \ln (t)^{2}}=0$ are presented in Table 3.

\section{Discussion}

The assessment of time series pore water pressure dissipation data required to calculate accurately the in situ equilibrium pore pressure is based on the identification of the minimum error resulting from the proposed numerical solution of the modified cavity expansion model. Prediction errors have been calculated from the difference between the measured $u_{\text {eq }}$ and the predicted one, $u_{\text {eq-cal }}$. The decrease of error with time has been evaluated for different sets of partial dissipation curves for the four sites A, B, C and D. From Figure 7, Figure 9 and Figure 11 and Table 3 it is clear that the minimum time series of pore water pressure dissipation data needed to accurately predict $u_{\text {eq }}$ corresponds to the time where $\frac{\partial^{2} u}{\partial \ln (t)^{2}}=0$. For time series data lower than the critical time where $\frac{\partial^{2} u}{\partial \ln (t)^{2}}=0$ and although the fitting between modelling results and observed data could be accurate for the considered time series, the prediction of the $u_{\text {eq }}$ may diverge significantly from the measured in situ equilibrium pore pressure (Figure 4-a, Figure 6-a, Figure 8-a and Figure 10-a). Figure 12 shows the residual between measured and calculated $u_{\text {eq }}$ versus $\frac{\partial^{2} u}{\partial \ln (t)^{2}}$ corresponding to the time series data used for the site $A$ calculations. It is clear that the residual value decreases drastically when $\frac{\partial^{2} u}{\partial \ln (t)^{2}}$ is approaching and exceeding zero. This was also observed for the three other sites (B, C and D).

One of the main aims of this work is also to verify the uniqueness of the numerical solution in terms of equilibrium pore water pressure $\left(u_{\text {eq }}\right)$ and in terms of geotechnical unknowns such as $C_{h}, C_{h s}, I_{r}$ and $\beta$. The uniqueness of the $u_{e q}$ seems evident whenever the available time series data show a concave-up curve in the $u-\ln (t)$ diagram. However, the uniqueness of the geotechnical parameters is not really established. This can be seen clearly from Figure 2 where $I_{r}$ and $C_{h}$ form a 2 two conjugate unknowns. One may expect to obtain the same numerical solution for infinite couples of $C_{h}$ and $I_{r}$ : longer dissipation paths (higher Ir) will match with higher permeability coefficients (higher $C_{h}$ ). Figure 13 illustrates the nonuniqueness of such parameters where two runs with two different set of parameters give almost the same pore-water dissipation curves (run 1 and run 2 in Figure 13). This nonuniqueness of $C_{h}$ and $I_{r}$ for a given dissipation curve was already demonstrated by Teh (1987) and Teh and Houlsby (1988) where the time factor $T^{*}$ was shown to depend on the coefficient of consolidation and the rigidity index. For a given $\mathrm{T}^{*}$, it is possible to have an infinite couples of $\mathrm{C}_{\mathrm{h}}$ and $\mathrm{I}_{\mathrm{r}}$. However, these back-calculations of the geotechnical parameters depend strongly on the type of expansion (spherical or cylindrical) generated by the piezoprobe penetration. Figure 13 illustrates that whatever the geometry of expansion is, it is possible to find a set of parameters where the numerical dissipation curve fits perfectly 
with the observed dissipation curve (run 3 in Figure 13). Therefore, the same dissipation curve may match with infinite couples of $\mathrm{Ir}$ and $\mathrm{C}_{\mathrm{h}}$ for cylindrical or spherical expansions surrounding the piezoprobe and therefore it seems impossible to derive $I_{r}$ and $C_{h}$ for unknown sediments and unknown expansion geometry from a dissipation pore water pressure curve alone.

\section{Conclusion}

In the present note, a modified cavity expansion approach was developed to simulate the pore water dissipation process by including two distinct zones surrounding a piezoprobe: the zone affected by shear and the plasticized zone. The coefficient of consolidation was considered to change linearly during the dissipation process as suggested by Abuel-Naga and Pender (2012).

The two main conclusions from this note are the following:

- The second derivative of pore pressure, $u$, versus the logarithmic of time, $t, \frac{\partial^{2} u}{\partial \ln (t)^{2}}$ must be positive in order to calculate accurately from partial measurements the in situ equilibrium pore water pressures $u_{\text {eq. }}$.

- A dissipation pore water pressure curve may match, for both cylindrical and spherical expansion cavities, with infinite couples of "rigidity index" and "coefficient of consolidation".

\section{References}

Abuel-Naga, H.M., Pender, M.J. 2012. Modified Terzaghi consolidation curves with effective stress-dependent coefficient of consolidation. Géotechnique Letters, Vol. 2 (2): 43-48.

Arulrajah, A., Nikraz, H., Bo, M.W. 2005. In-situ testing of Singapore marine clay at Changi. Geotechnical and Geological Engineering, Vol. 23 (2): 111-130. doi: 10.1007/s10706-0037329-0.

Baligh, M.M. 1986. Strain Path Method. Journal of Geotechnical Engineering, 111 (9): 11081136.

Biscontin, G., Pestana, J.M. 2006. Factors affecting seismic response of submarine slopes. Natural hazards and earth system sciences, Vol. 6 (1): 97-107.

Burns, S.E., Mayne, P.W. 1998. Monotonic and dilatory pore-pressure decay during piezocone tests in clay. Canadian Geotechnical Journal, 35:1063-1073. doi: 10.1139/cgi35-6-1063.

Burns, S.E., Mayne, P.W. 1999. Pore pressure dissipation behavior surrounding driven piles and cone penetrometers. Transportation Research Record 1675, Paper No. 99-0423.

Burns, S.E., Mayne, P.W. 2002. Analytical cavity expansion-critical state model for piezocone dissipation in fine-grained soils. Soils and Foundations, 42 (2): 131-137.

Davis, E.E., Horel, G.C. and MacDonald, R.D. 1991. Pore pressures and permeabilities measured in marine sediments with a tethered probe. Journal of Geophysical Research, 96 (B4): 5975-5984. doi:10.1029/91JB00220.

Dugan, B. and Flemings, P.B. 2000. Overpressure and fluid flow in the New Jersey continental slope: implications for slope failure and cold seeps. Science, 289: 288-291.

Dugan, B. and Flemings, P.B. 2002. Fluid flow and stability of the US continental slope offshore New Jersey from the Pleistocene to the present. Geofluids, 2: 137-146. doi: 10.1046/j.1468-8123.2002.00032. 
Dugan, B. and Germaine, J.T. 2008. Near-seafloor overpressure in the deepwater Mississippi Canyon, northern Gulf of Mexico. Geophysical Resarch Letters, 35, L02304. doi: 10.1029/2007GL03275.

Flemings, P.B., Long, H., Dugan, B., Germaine, J., John, C., Behrmann, J., Sawyer, D. and Expedition 308 Scientists 2008. Overpressures in the Ursa Basin, Deepwater Gulf of Mexico: Results from IODP Expedition 308. Earth and Planetary Science Letters, 269: 309-325.

Haeussler, P., Lee, H., Ryan, H., Labay, K., Suleimani, E., Alexander, C., Kayan, R. 2008. Submarine Landslides and Tsunamis at Seward and Valdez Triggered by the 1964 Magnitue 9.2 Alaska Earthquake. Newsletter Alaska Geology, 39 (2): 1-2.

Kim, Y.S., Lee, S.R. 2000. Prediction of long-term pore pressure dissipation behavior by short-term piezocone dissipation test. Computers and Geotechnics, 27: 273-287.

Kvalstad, T. J., Andresen, L., Forsberg, C.F., Berg, K., Bryn, P., Wangen, M. 2005. The Storegga slide: evaluation of triggering sources and slide mechanics. Marine and Petroleum Geology, 22: 245-256. doi: 10.1016/j.marpetgeo.2004.10.019.

Lacasse, S., Lunne, T. 1982. Penetration tests in two Norwegian clays. In Proceedings , $2^{\text {nd }}$ European Symposium on Penetration Testing, Amsterdam, Vol. 2: 661-669.

Lafuerza, S. Sultan, N., Canals, M., Frigola, J., Berne, S., Jouet, G., Galavazi, M., Sierro, F. J. 2009. Overpressure within upper continental slope sediments from CPTU data, Gulf of Lion, NW Mediterranean Sea. International Journal of Earth Sciences, 98(4): 751-768. doi: $10.1007 / \mathrm{s} 00531-008-0376-2$.

Lee, H.J., Locat, J., Desgagné, P., Parsons, J.D., McAdoo, B.G., Orange, D.L., Puig, P., Wong, F.L., Dartnell, P., Boulanger, E. 2007. Submarine mass movements on continental margins: A review of triggering mechanisms and preconditions to failure. In Continental Margin Sedimentation: from sediment transport to sequence stratigraphy. I. Jarvis (ed.). Special publication of the International Association of Sedimentologists, 37: 213-274. doi: 10.1016/j.marpetgeo.2008.02.008.

Leynaud, D, Sultan N., Mienert, J. 2007. The role of sedimentation rate and permeability in the slope stability of the formerly glaciated Norwegian continental margin: the Storegga slide model. Landslides. doi: 2008020002513722-0001.

Long, H., Flemings, P.B., Germaine, J.T. 2007. Interpreting in situ pressure and hydraulic properties with borehole penetrometers in ocean drilling: DVTPP and Piezoprobe deployments at southern Hydrate Ridge, offshore Oregon. Journal of Geophysical research, 112, B04101. doi: 10.1029/2005JB004165.

Lunne, T., Berre, T., Andersen, K.H., Strandvik, S., Sjursen, M. 2006. Effects of sample disturbance and consolidation procedures on measured shear strength of soft marine Norwegian clays. Canadian Geotechnical Journal, 43: 726-750. doi: 10.113/T06-040.

Masson, D.G., Wynn, R.B., Talling, P.J. 2010. Large landslides on passive continental margins: processes, hypotheses and outstanding questions. In: Mosher, D.C., Shipp, C., Moscardelli, L., Chaytor, J., Baxter, C., Lee, H., Urgeles, R. (Eds.), Submarine Mass movements and their consequences IV. Advances in Natural and Technological Hazards Series 28, Springer: 153-165.

Nixon, M.F., Grozic, J.L.H. 2007. Submarine slope failure due to gas hydrate dissociation: a preliminary quantification. Canadian Geotechnical Journal, 44: 314-325. doi: 10.1139/T06121.

Riboulot, V., et al., in press. Gas seeps controlled by a buried submarine landslide and sealevel changes. EPSL.

Schneider, J., Flemings, P., Dugan, B., Long, H., Germaine, J.T. 2009. Overpressure and consolidation near the seafloor of Brazos-Trinity Basin IV, northwest deepwater Gulf of Mexico. Journal of Geophysical Research, 4, B05102. doi: 1029/2008JB005922.

Stegmann, S., Strasser, M., Anselmetti, F., Kopf, A. 2007. Geotechnical in situ characterization of subaquatic slopes: The role of pore pressure transients versus frictional strength in landslide initiation. Geophysical Research Letters, 34, L07607. doi: 10.1029/2006GL029122. 
Stegmann, S., Sultan, N., Kopf, A., Apprioual, R., Pelleau, P. 2011. Hydrogeology and its effect on slope stability along the coastal aquifer of Nice, France. Marine Geology. doi:10.1016/j.margeo.2010.12.009

Strout, J.M., Tjelta, T.I. 2005. In situ pore pressures: What is their significance and how can they be reliable measured?. Marine and Petroleum Geology, 22: 275-285. doi: 10.1016/j.marpetgeo.2004.10.024.

Sully, J.P., Robertson, P.K., Campanella, R.G., Woeller, D.J. 1999. An approach to evaluation of field CPTU dissipation data in overconsolidated fine-grained soils. Canadian Geotechnical Journal, 36: 369-381. doi:10.1139/cgj-36-2-369.

Sultan, N., Cattaneo, A., Urgeles, R., Lee, H., Locat, J., Trincardi, F., Berne, S., Canals, M., Lafuerza, S. 2008. A geomechanical approach for the genesis of sediment undulations on the Adriatic shelf. Geochem. Geophys. Geosyst. doi:10.1029/2007GC001822.

Sultan, N., Marsset, B., Ker, S., Marsset, T., Voisset, M., Vernant, A.,M., Bayon, G., Cauquil, E., Adamy, Colliat, J.L., Drapeau, D. 2010. Hydrate dissolution as a potential mechanisms for pockmark formation in the Niger delta. Journal of Geophysical Research, 115, B08101. doi: 10.1029/2010JB007453.

Sultan, N., Riboulot, V. Ker, S., Marsset, B., Géli, L., Tary, J.B., Klingelhoefer, F., Voisset, M., Lanfumey, V., Colliat, J.L., Adamy, J., Grimaud, S. 2011. Dynamics of fault-fluidhydrate system around a shale-cored anticline in deepwater Nigeria. J. Geophys. Res Solid Earth. doi: 10.1029/2011JB008218.

Teh, C.I. 1987. An analytical study of the cone penetration test. D.Phil. thesis, Oxford University, Oxford, U.K.

Teh, C.I., and Houlsby, G.T. 1988. Analysis of the cone penetration test by the strain path method. In Proceedings of the 6th International Conference on Numerical Methods in Geomechanics, Innsbruck.

Urgeles, R., Masson, D.G., Canals, M., Watts, A.B., Le Bas, T. 1999. Recurrent large-scale landsliding on the west flank of La Palma, Canary Islands. Journal of Geophysical reseaarch, 104: 25331-25348. doi:10.1029/1999JB900243.

Urgeles, R., Canals, M., Roberts, J. and the SNV "Las Palmas" Shipboard Party. 2000. Fluid flow from pore pressure measurements off La Palma, Canary Islands. Journal of Volcanology and Geothermal research, 101: 253-271. doi:10.1016/S03770273(00)00176-1. 
Table 1. Main characteristics of the four studied sites and input parameters used for model predictions. For sites $A, C$ and $D$, the zone affected by shear is considered as negligible and therefore $\mathrm{C}_{\mathrm{hs}}$ and $\mathrm{u}_{\mathrm{in}}$ were not used in the calculation (grey areas in the table).

\begin{tabular}{ccccc}
\hline Site & $\begin{array}{c}\text { A } \\
\text { Nice slope }\end{array}$ & $\begin{array}{c}\text { B } \\
\text { Niger Delta }\end{array}$ & $\begin{array}{c}\text { C } \\
\text { Niger Delta }\end{array}$ & $\begin{array}{c}\text { D } \\
\text { Algerian margin }\end{array}$ \\
\hline Site name & PZ2Y03-P7 & ER-PZS12-P5 & GM-PZ05-P4 & PZ1-15-P3 \\
depth [mbsf] & 8.58 & 11.48 & 8.48 & 5.5 \\
$\mathbf{r}_{\mathbf{0}}[\mathrm{m}]$ & 0.03 & 0.03 & 0.03 & 0.03 \\
Range $\mathbf{C}_{\mathrm{h}}\left[\mathrm{m}^{2} / \mathbf{s}\right]$ & $10^{-10} \rightarrow 2 \times 10^{-6}$ & $10^{-9} \rightarrow 10^{-6}$ & $10^{-10} \rightarrow 10^{-6}$ & $10^{-9} \rightarrow 10^{-6}$ \\
Range $\beta[-]$ & $0.1 \rightarrow 0.999$ & $0.1 \rightarrow 0.999$ & $0.1 \rightarrow 0.999$ & $0.1 \rightarrow 0.999$ \\
Range $\mathbf{C}_{\mathrm{hs}}\left[\mathrm{m}^{2} / \mathbf{s}\right]$ & & $10^{-7} \rightarrow 10^{-5}$ & & \\
Range $\mathbf{I}_{\mathrm{r}}[-]$ & $45 \rightarrow 250$ & $40 \rightarrow 400$ & $45 \rightarrow 450$ & $40 \rightarrow 400$ \\
Range $\mathbf{u}_{\mathrm{i}}[\mathrm{kPa}]$ & $90 \rightarrow 300$ & $10 \rightarrow 150$ & $60 \rightarrow 600$ & $60 \rightarrow 350$ \\
Range $\mathbf{u}_{\text {in }}[\mathrm{kPa}]$ & & $130 \rightarrow 300$ & & $-45 \rightarrow 45$ \\
Range $\mathbf{u}_{\text {eq }}[\mathrm{kPa}]$ & $-50 \rightarrow 50$ & $-70 \rightarrow 70$ & $-40 \rightarrow 50$ & $4 \times 10^{7}$ \\
\# of calculations & $4 \times 10^{7}$ & $4 \times 10^{7}$ & $4 \times 10^{7}$ & \\
\hline
\end{tabular}

Table 2. $u_{\text {eq }}$ and time needed for $\frac{\partial^{2} u}{\partial \ln (t)^{2}}$ to reach 0 for the four studied sites.

\begin{tabular}{ccccc}
\hline Site & A & B & C & D \\
\hline $\begin{array}{c}\mathbf{u}_{\text {eq }}[\mathrm{kPa}] \\
\text { Time where }\end{array}$ & 0.7 & 2.4 & 0.0 & 0.1 \\
$\frac{\partial^{2} u}{\partial \ln (t)^{2}}=0[\mathbf{s}]$ & 11919 & 46304 & 31350 & 31377 \\
\hline
\end{tabular}


Table 3. Calculated $u_{\text {eq-cal }}$ from data recorded until $\frac{\partial^{2} u}{\partial \ln (t)^{2}}=0$ compared to extrapolated $u_{\text {eq- }}$ ext based on the Davis et al. (1991) method. For sites A, C and D, the zone affected by shear is considered as negligible and therefore $C_{h s}$ and $u_{i n}$ were not used in the calculation (grey areas in the table).

\begin{tabular}{ccccc}
\hline Site & A & B & C & D \\
\hline$\left|\mathbf{u}_{\text {eq }}-\mathbf{u}_{\text {eq-cal }}\right|[\mathrm{kPa}]$ & 3.5 & 1.9 & 0.4 & 2.1 \\
$\left|\mathbf{u}_{\text {eq }}-\mathbf{u}_{\text {eq-ext }}\right|[\mathrm{kPa}]$ & 6.4 & 9 & 2.7 & 1.0 \\
$\mathbf{C}_{\mathrm{h}}\left[\mathrm{m}^{2} / \mathbf{s}\right]$ & $4.5 \times 10^{-7}$ & $5.9 \times 10^{-8}$ & $6.5 \times 10^{-7}$ & $3.0 \times 10^{-7}$ \\
$\beta[-]$ & 0.15 & 0.33 & 0.76 & 0.45 \\
$\mathbf{C}_{\mathrm{hs}}\left[\mathrm{m}^{2} / \mathbf{s}\right]$ & & $910^{-6}$ & & 68 \\
$\mathbf{I}_{\mathbf{r}}[-]$ & 49.8 & 187 & 97 & 93.2 \\
$\mathbf{u}_{\mathrm{i}}[\mathrm{kPa}]$ & 153 & 95.8 & 86.6 & \\
$\mathbf{u}_{\text {in }}[\mathrm{kPa}]$ & & 149.8 & & \\
\hline
\end{tabular}

\section{Figures}

Figure 1. Conceptual dissipation curves of normally consolidated soils (diamonds) and of overconsolidated soils (crosses) (modified from Burns and Mayne, 1999).

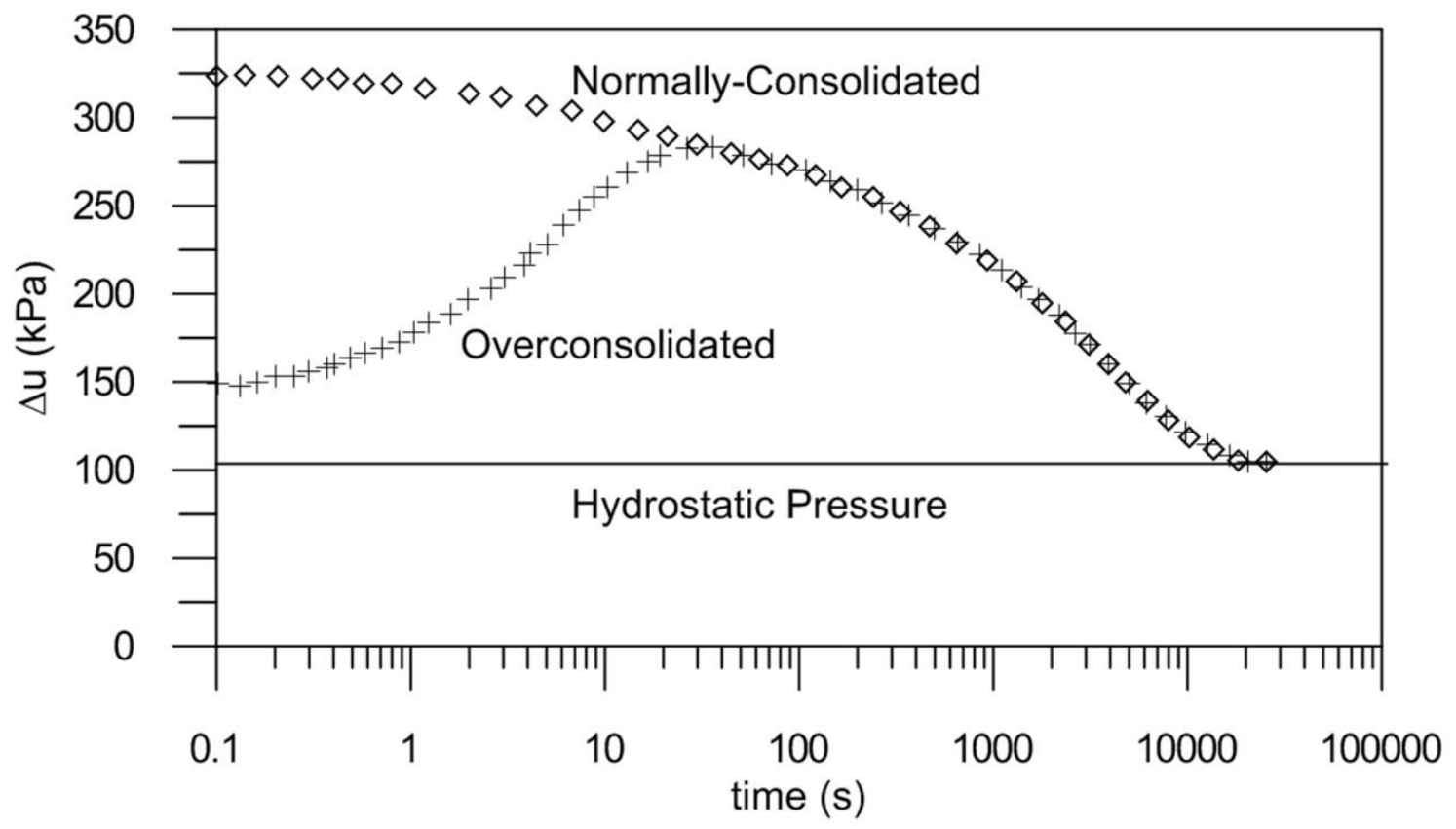


Figure 2. Zones affected by piezometer penetration. $r_{o}$, cone radius; $r_{p}$, radius of plasticized zone; $\mathrm{C}_{\mathrm{h}}$, consolidation coefficient of plasticised zone; $\mathrm{C}_{\mathrm{hs}}$, consolidation coefficient of zone affected by shear; $u_{i}$, pore-water pressure measured by pore pressure sensor at time $0^{+}$and $\mathrm{u}_{\mathrm{in}}$, pore-water pressure generated at the interface between zone affected by shear and plasticized at time $0^{+}$(notation follows Burns and Mayne 1998).

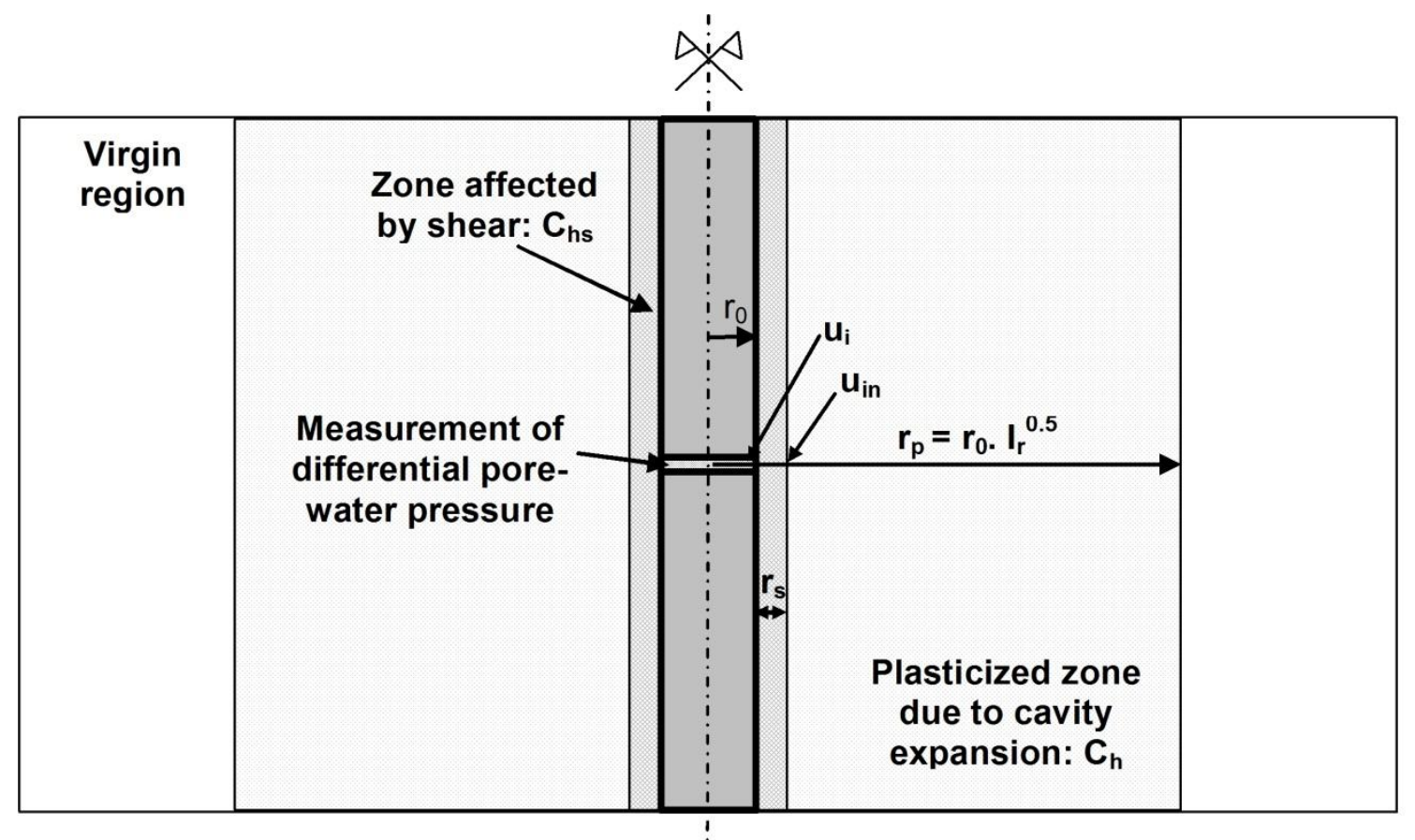


Figure 3. Schematic procedure similar to the one proposed by Kim and Lee (2000) for predicting long-term pore pressure dissipation behaviour.

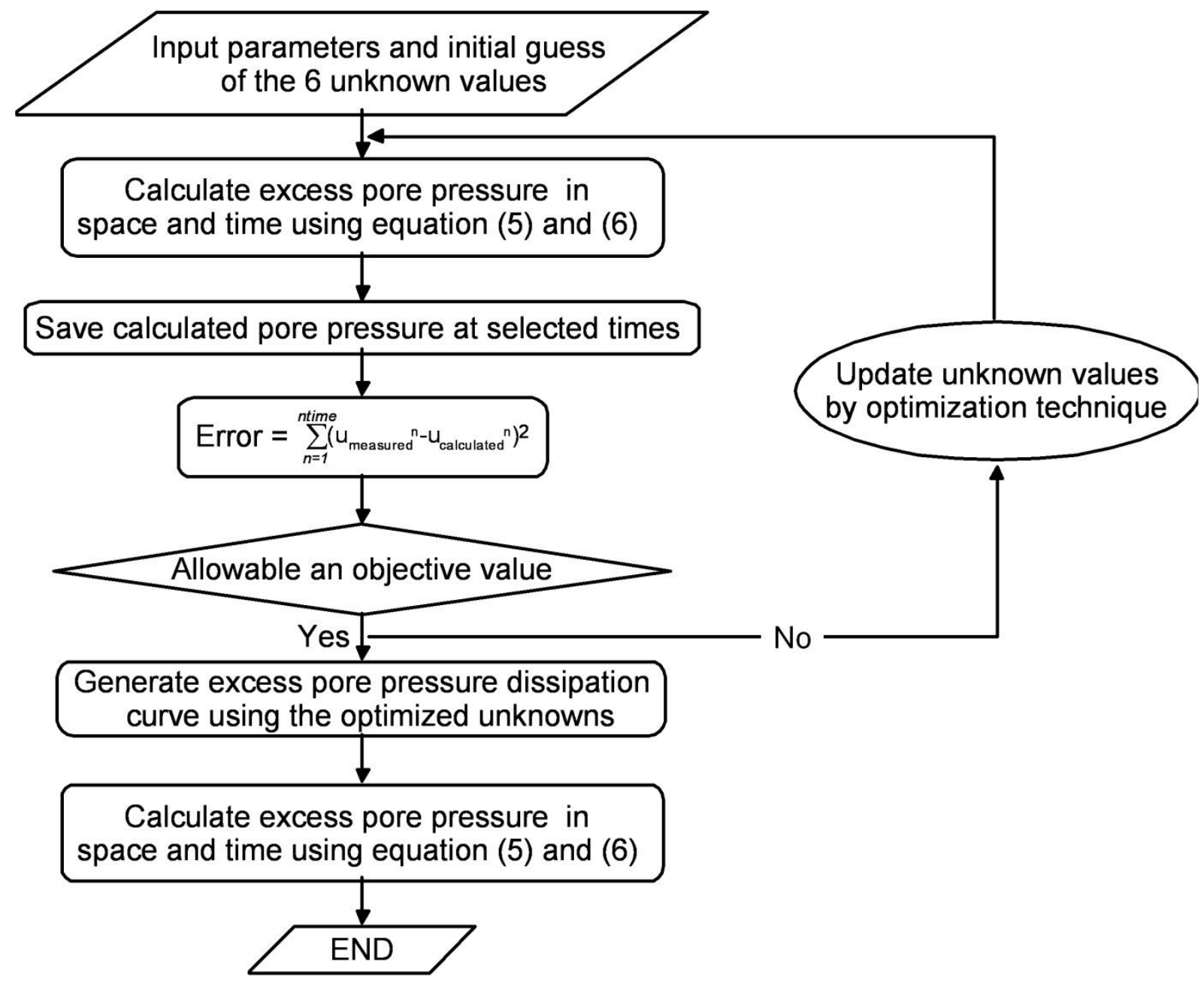


Figure 4. Site A - Nice slope: model predictions in marine clay based on pore-water pressure dissipation recorded during (a) 1 hour, 2 and 3 hours and (b) 4, 6, 8 and 10 hours. The full range of pore-water pressure dissipation data are also plotted (dashed lines) in (a) and (b).
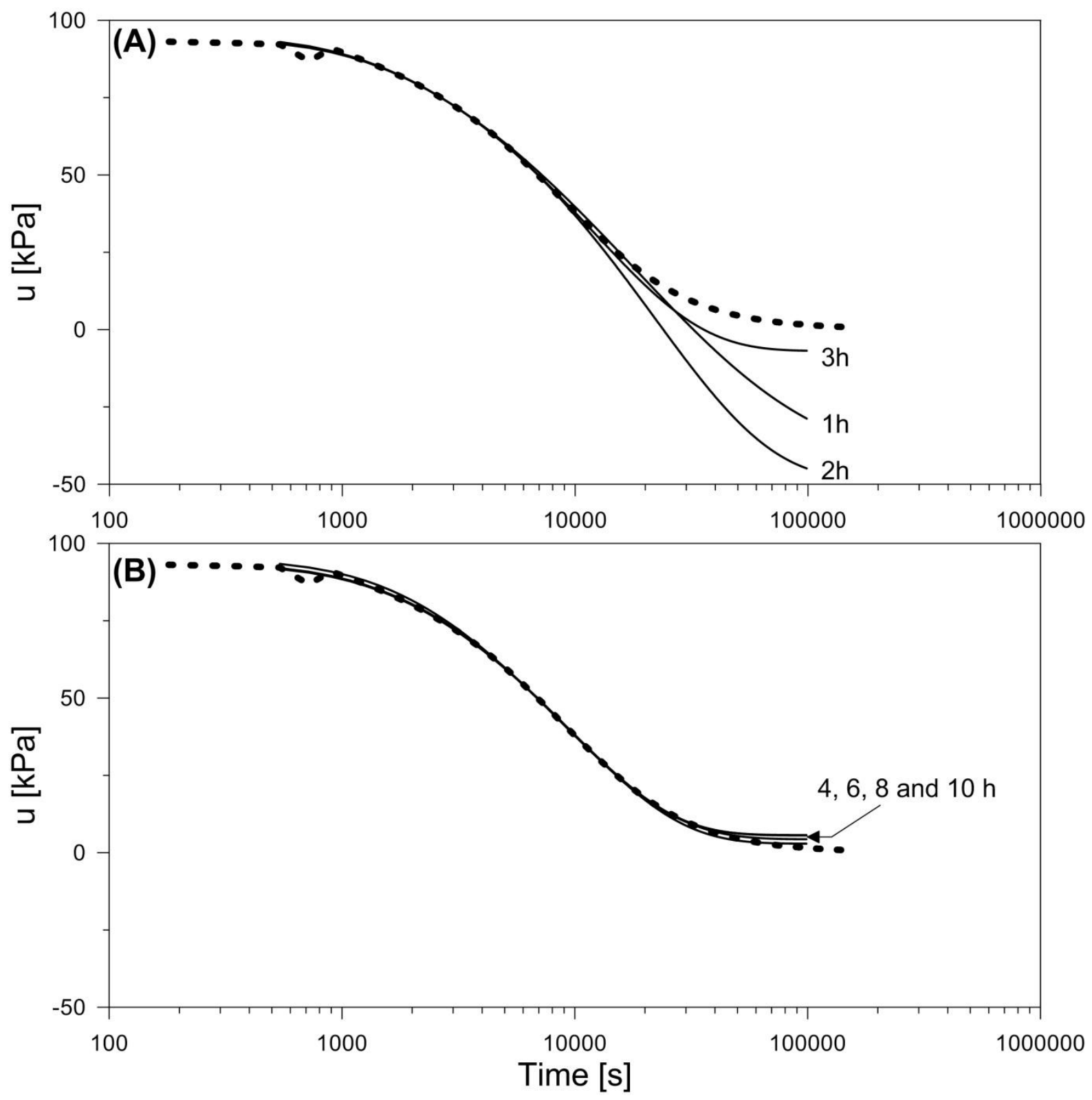
Figure 5. Site A - Nice slope: a) pore pressure, u, first derivative, $\frac{\partial u}{\partial \ln (t)}$ and second derivative $\frac{\partial^{2} u}{\partial \ln (t)^{2}}$ of $u$ versus the logarithmic of time and (b) predicted $u_{\text {eq }}$ as a function of the time series data used for calculation. Each $u_{\text {eq }}$ plotted values (open circles) correspond to a set of parameters where the error between predicted and observed $u_{\text {eq }}$ is less than 1.5 times the minimum error obtained using the least-squares minimization.
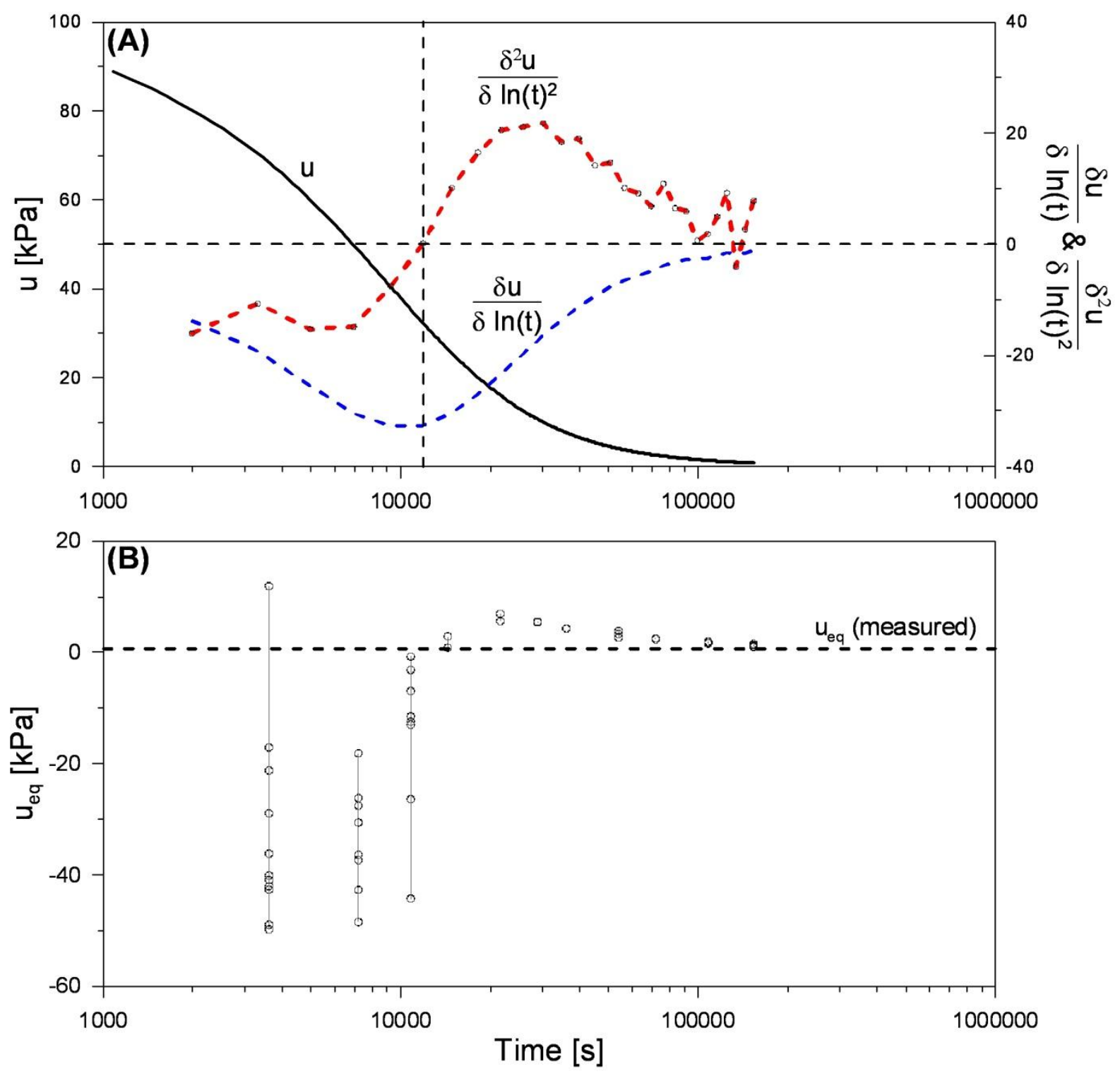
Figure 6. Site B - Niger delta: model predictions in marine plastic clay based on pore-water pressure dissipation recorded during (a) 2, 4, 6, 8, 12 and 15 hours and (b) 24, 28, 30 and 36 hours. The full range of pore-water pressure dissipation data are also plotted (dashed lines) in (a) and (b).
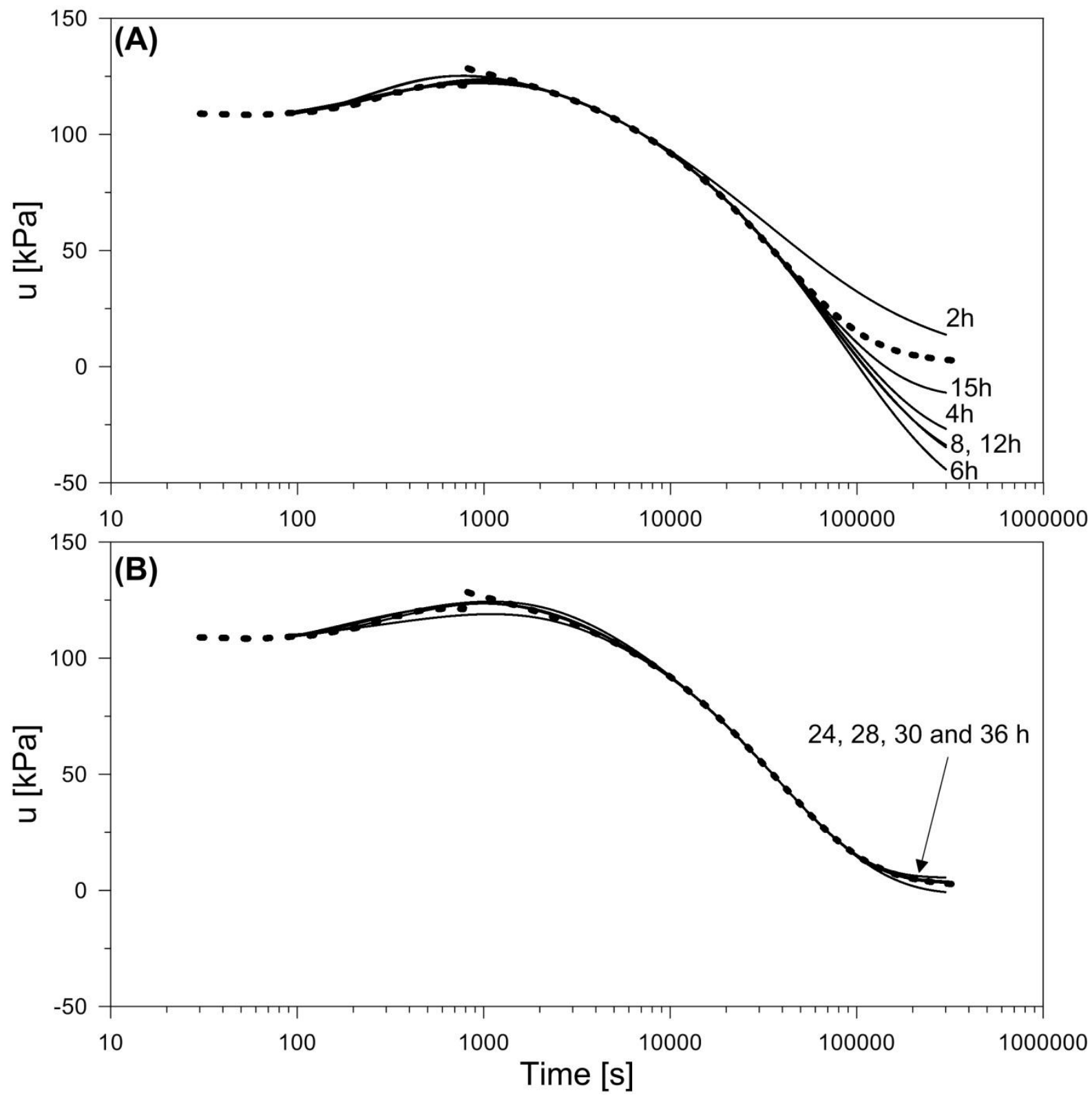
Figure 7. Site b-Niger delta: a) $u, \frac{\partial u}{\partial \ln (t)}$ and $\frac{\partial^{2} u}{\partial \ln (t)^{2}}$ versus the logarithmic of time and (b) predicted $u_{e q}$ as a function of the time series data used for calculation. Each $u_{\text {eq }}$ plotted values (open circles) correspond to a set of parameters where the error between predicted and observed $u_{\text {eq }}$ is less than 1.5 times the minimum error obtained using the least-squares minimization.
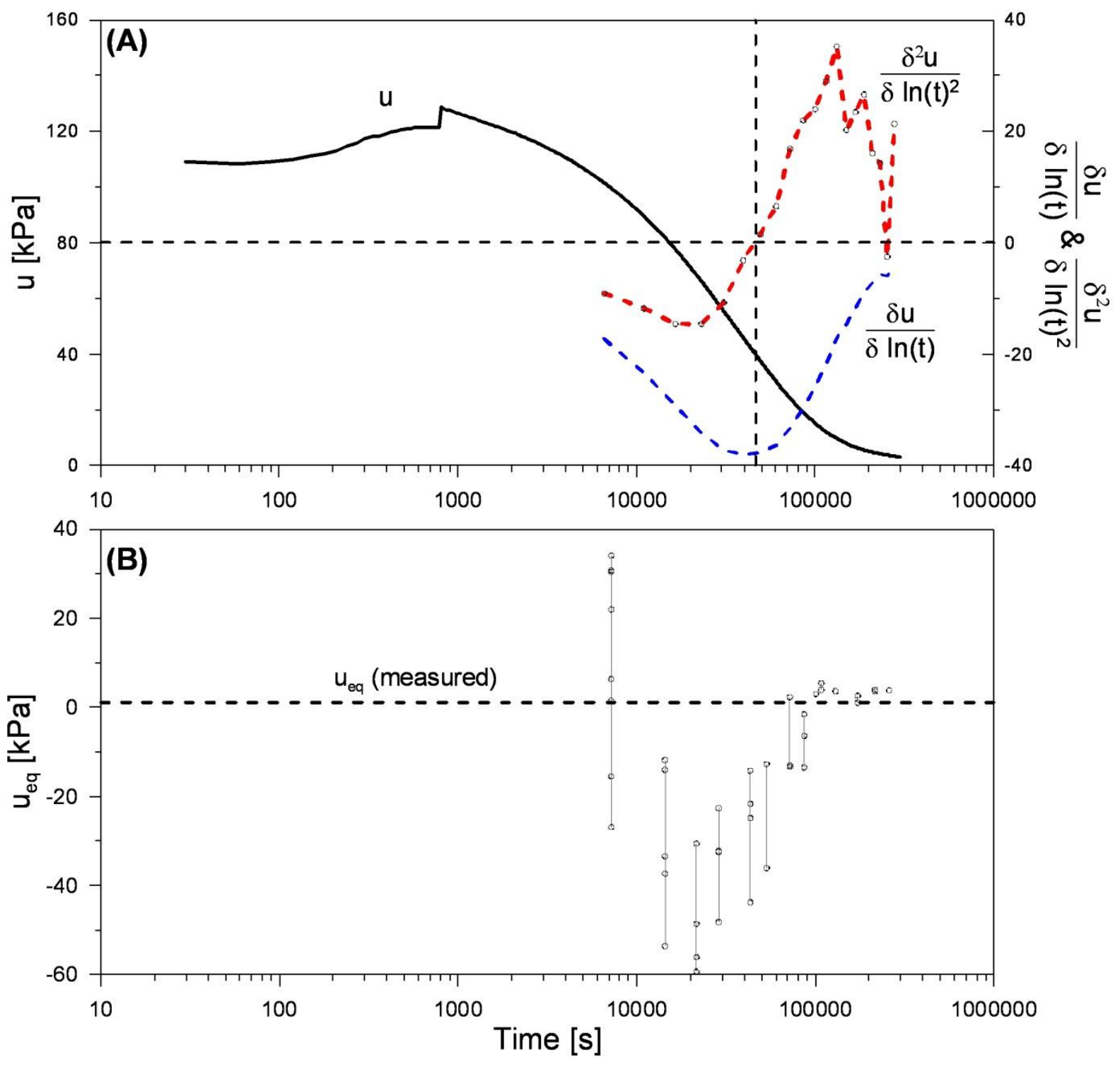
Figure 8. Site $\mathrm{C}$ - Niger delta: model predictions in marine plastic clay based on pore-water pressure dissipation recorded during (a) 2, 3 and 5 hours and (b) 8, 10, 15 and 20 hours. The full range of pore-water pressure dissipation data are also plotted (dashed lines) in (a) and (b).
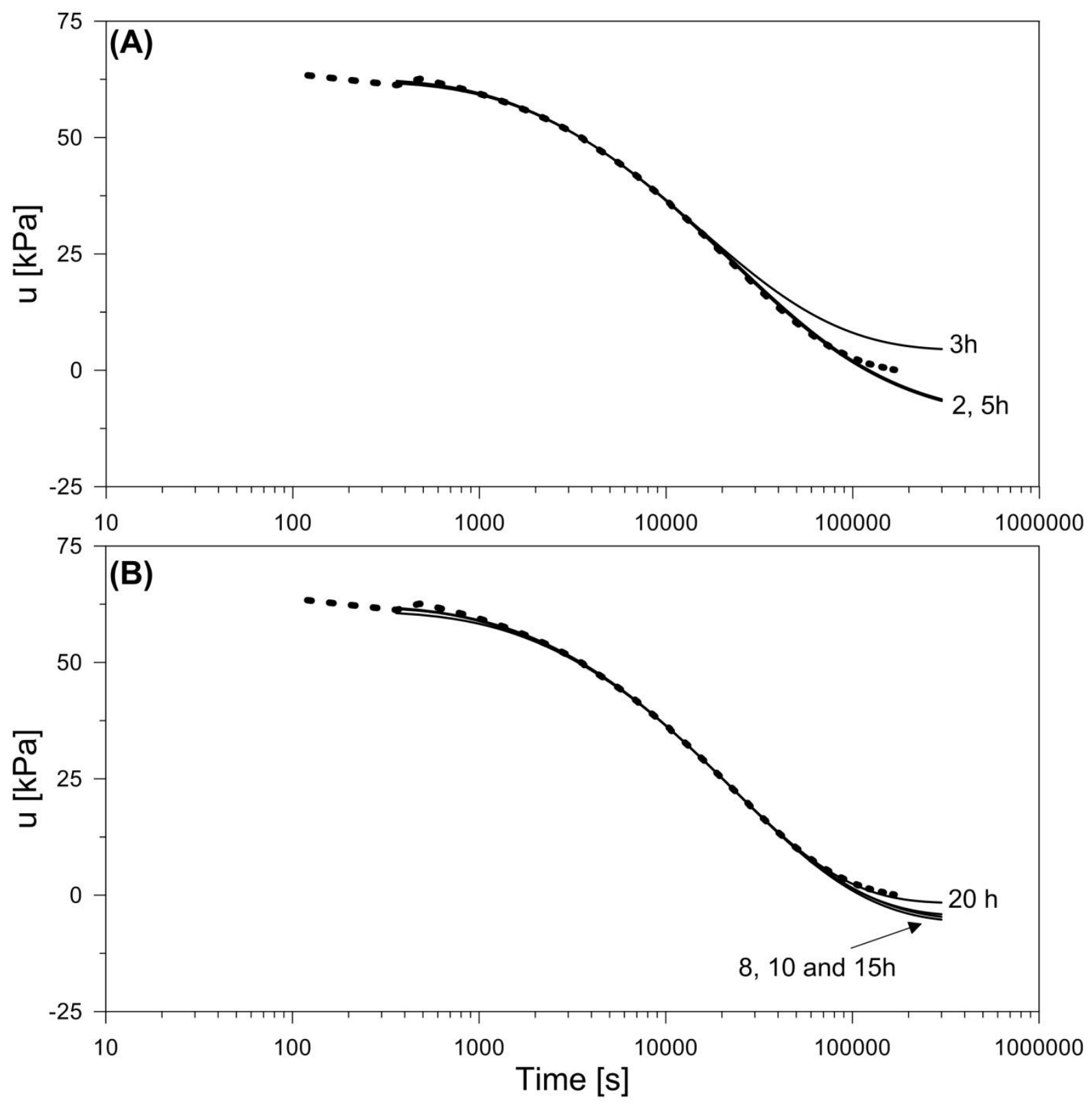
Figure 9. Site $\mathrm{C}-$ Niger delta: a) $\mathrm{u}, \frac{\partial u}{\partial \ln (t)}$ and $\frac{\partial^{2} u}{\partial \ln (t)^{2}}$ versus the logarithmic of time and (b) predicted $u_{\text {eq }}$ as a function of the time series data used for calculation. Each $u_{\text {eq }}$ plotted values (open circles) correspond to a set of parameters where the error between predicted and observed $u_{\text {eq }}$ is less than 1.5 times the minimum error obtained using the least-squares minimization.
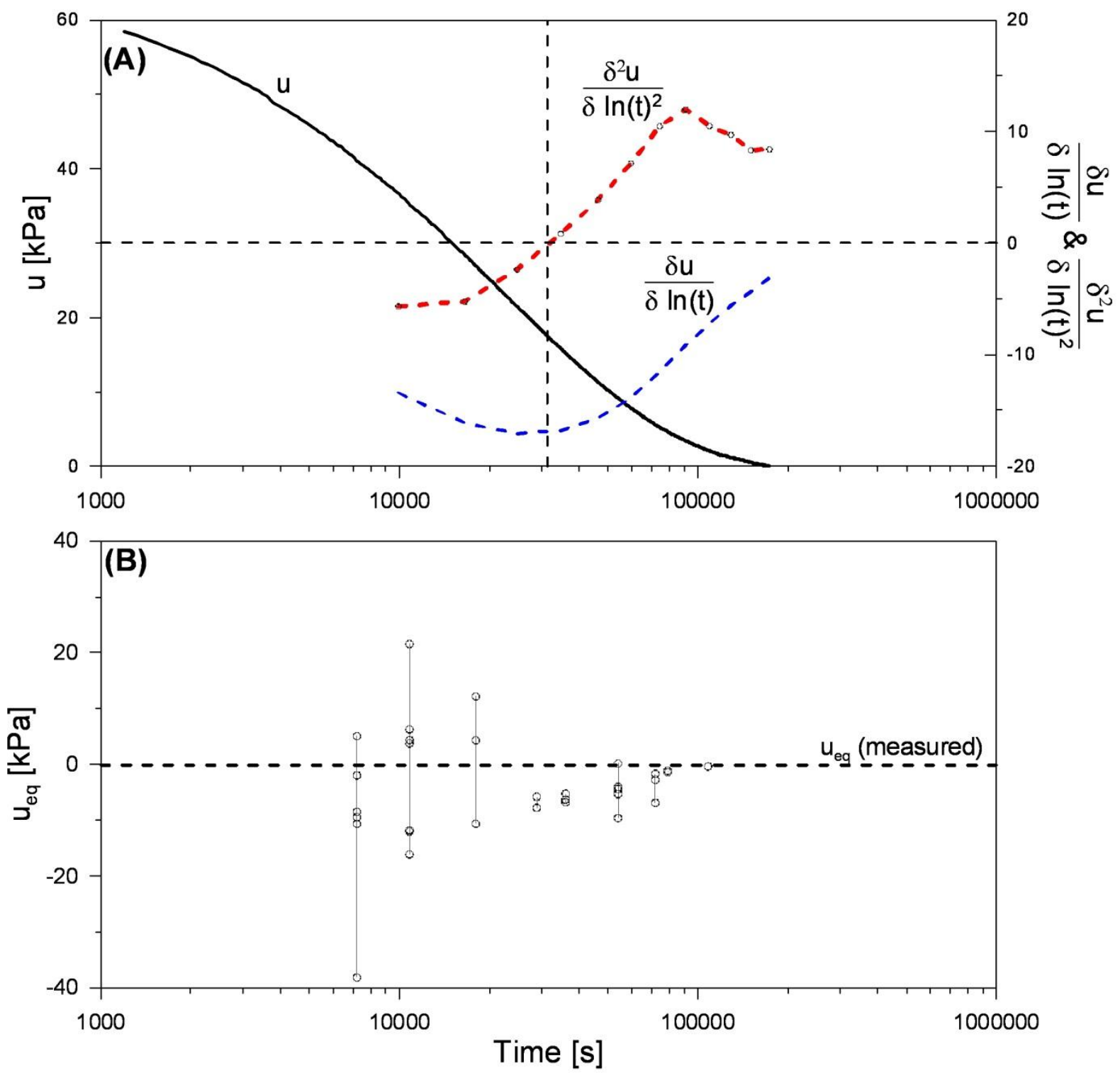
Figure 10. Site D - Algerian margin: model predictions in marine silty-clay based on porewater pressure dissipation recorded during (a) 2, 4, 6 and 8 hours and (b) 10, 12 and 15 hours. The full range of pore-water pressure dissipation data are also plotted (dashed lines) in (a) and (b).
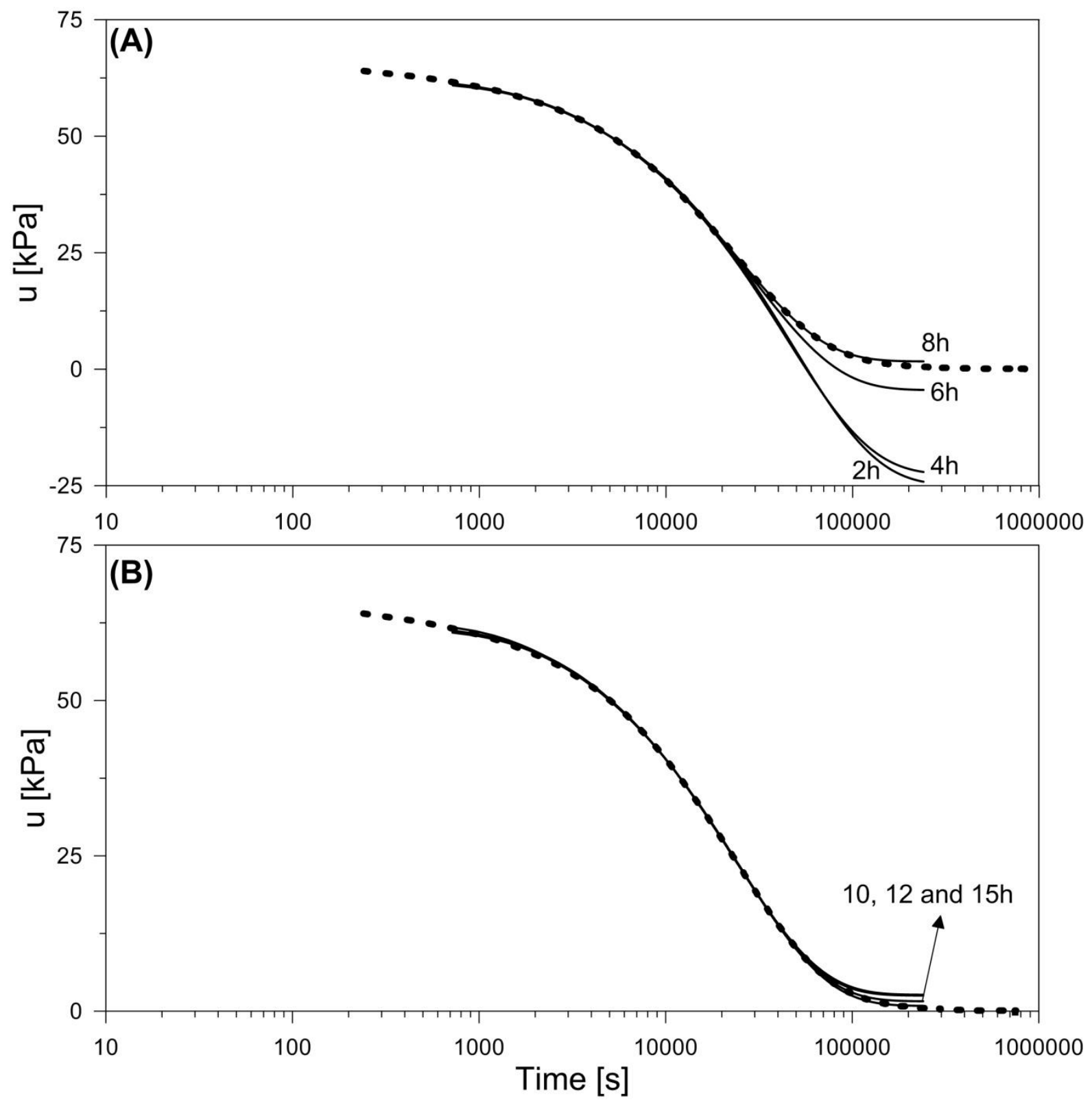
Figure 11. Site $D$ - Algerian margin: a) $u, \frac{\partial u}{\partial \ln (t)}$ and $\frac{\partial^{2} u}{\partial \ln (t)^{2}}$ versus the logarithmic of time and (b) predicted $u_{\text {eq }}$ as a function of the time series data used for calculation. Each $u_{e q}$ plotted values (open circles) correspond to a set of parameters where the error between predicted and observed $u_{\mathrm{eq}}$ is less than 1.5 times the minimum error obtained using the leastsquares minimization.
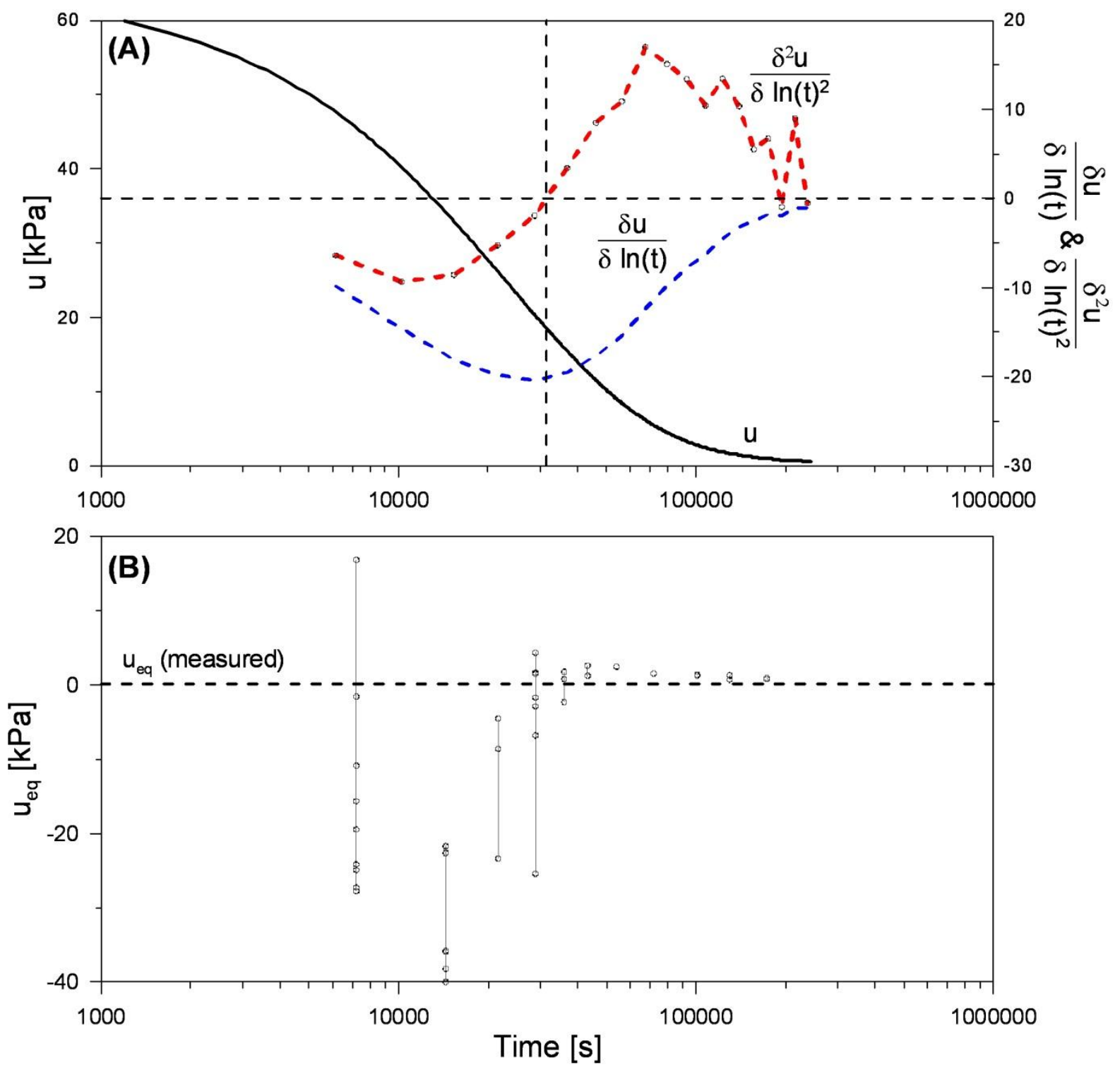
Figure 12. Site A - Nice slope: The residual between measured and calculated $u_{\text {eq }}$ versus $\frac{\partial^{2} u}{\partial \ln (t)^{2}}$ corresponding to the time series data used for each calculations. This residual decreases drastically when $\frac{\partial^{2} u}{\partial \ln (t)^{2}}$ is approaching and exceeding zero.

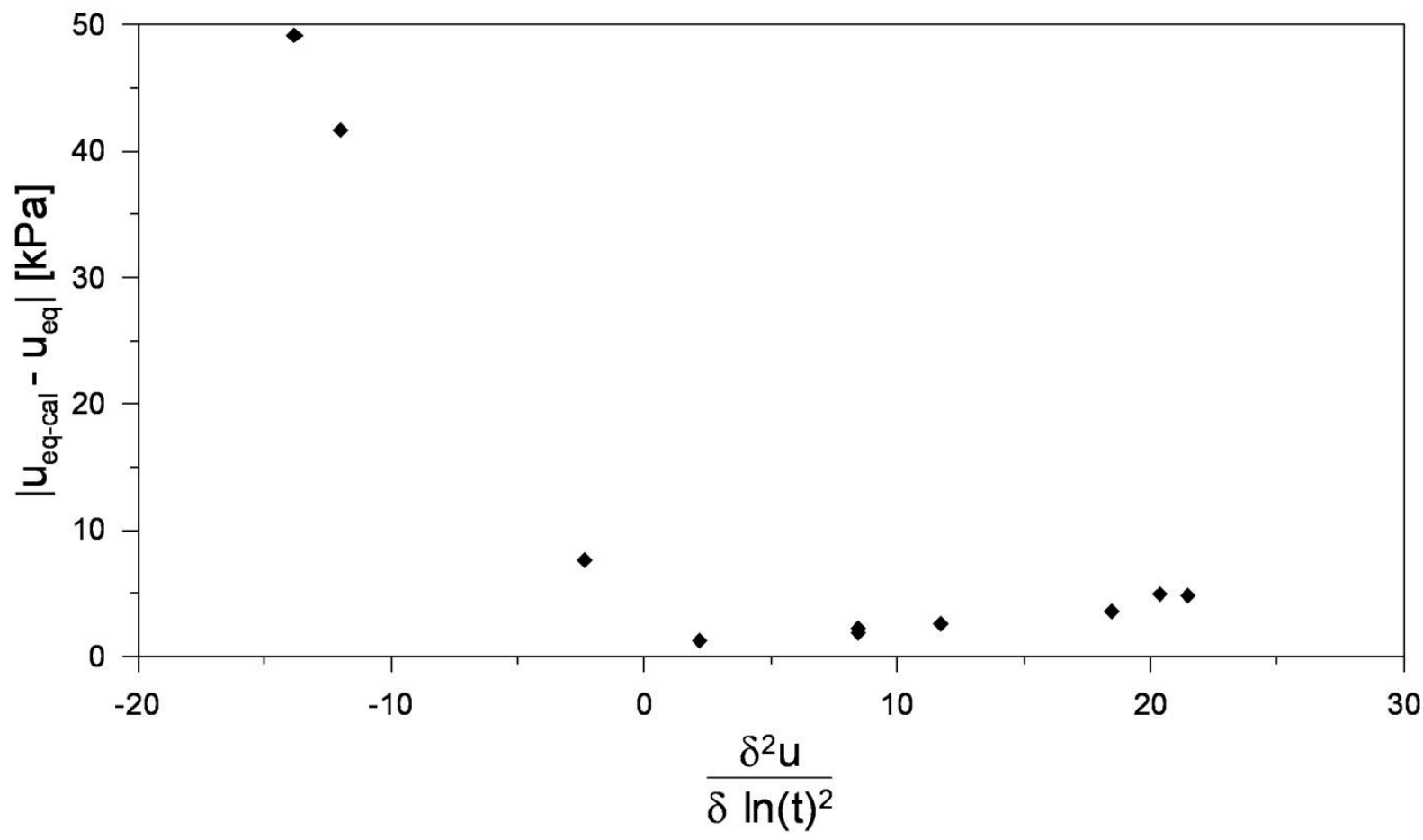

Figure 13. Site A - Nice slope: three runs with three different set of parameters giving similar pore-water dissipation curves. The full range of pore-water pressure dissipation data are also plotted (dashed line).

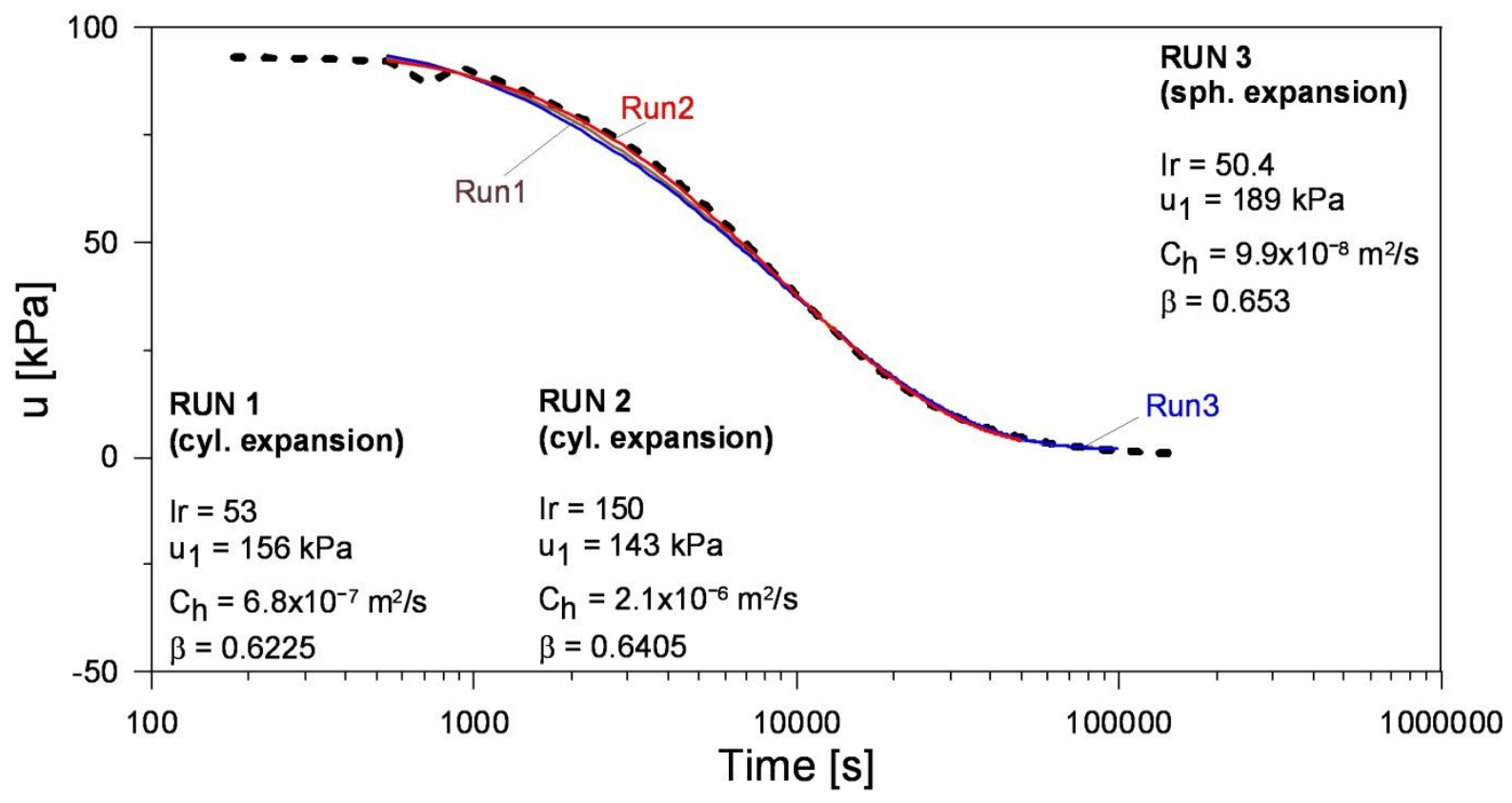

